\title{
UROLIFT FOR THE TREATMENT OF LOWER URINARY TRACT SYMPTOMS IN A PATIENT WITH AMS 700 PENILE PROSTHESIS: THE FIRST REPORTED CASE
} Adam Jones, YC Phan, Wasim Mahmalji

Department of Urology, Hereford County Hospital, Hereford, Herefordshire, UK

Corresponding author apjones47@doctors.org.uk

Submitted: December 1, 2018. Accepted: Dec 24, 2018. Published: January 14, 2019.

\begin{abstract}
The UroLift system (Teleflex Inc.) is a minimally invasive and non-ablative technique used for the treatment of male lower urinary tract symptoms (LUTS) caused by benign prostatic hyperplasia. It has been introduced as an alternative to transurethral resection of the prostate (TURP) to avoid any unwanted side effects such as erectile dysfunction, hospital stay and catheterization. A 68-year old patient with bothersome LUTS and significant co-morbidities presented for consideration of UroLift to avoid the risks associated with more invasive TURP surgery. The patient had previously had an AMS 700 MS implanted penile prosthesis (IPP) inserted for erectile dysfunction refractory to medical therapy. To the authors best knowledge, there have been no reports or published literature on the use of the UroLift device to treat male LUTS in the presence of an IPP. This case report aims to present this unique case and discuss operative technique for use of the UroLift device in the presence of an IPP.
\end{abstract}

The UroLift system (Teleflex Inc.) is a minimally invasive technology developed to treat bothersome lower urinary tract symptoms (LUTS) as a result of benign prostatic hyperplasia $(\mathrm{BPH}) .{ }^{1}$ The National Institute for Health and Care Excellence (NICE) recommends use of the UroLift system (Figure 1) for treating LUTS in BPH. ${ }^{2}$

There are many advantages of the UroLift system as opposed to transurethral resection of prostate (TURP) for BPH refractory to medical therapy. The advantages of this non-ablative and minimally invasive procedure include documented improvement in functional outcomes and avoiding common complications such as bleeding, TUR syndrome, ejaculatory and erectile dysfunction (ED) associated with TURP ${ }^{(1)}$.

Here, we report our unique experience of UroLift for the treatment of LUTS in a patient with an inflatable penile prosthesis (IPP). To our best knowledge, there is no reported literature on the use of the UroLift device in a patient with an IPP.

\section{BACKGROUND}

A 68-year old gentleman presented to the urology outpatients department with an 18-month history of bothersome LUTS. His main complaints were poor flow, hesitancy, and nocturia of up to 4 episodes each night. There was no history of urge or incontinence, and the patient denied any recurrent urinary tract infection and visible hematuria. Examination revealed a benign feeling prostate gland. International Prostate Symptom Score (IPSS) while taking tamsulosin confirmed mild LUTS with a total of 4, his Quality-of-Life (QoL) was 3. International Index of Erectile Function (IIEF) score was 13 but interpreted with caution, as an inflatable penile prosthesis (IPP) was in situ.

Although on IPSS he did not appear to be greatly symptomatic, the patient had stopped taking his tamsulosin as he considered this to be negatively affecting his cardiac function. As a result, his LUTS deteriorated rapidly and he restarted his tamsulosin

J Endolum Endourol Vol 2(1):e5-e12; January 14, 2019.

This article is distributed under the terms of the Creative Commons Attribution-Non

Commercial 4.0 International License. (C2019 Jones et al. 
FIG. 1 UroLift device and UroLift Implant. Images provided courtesy of Teleflex Inc.. All rights reserved.

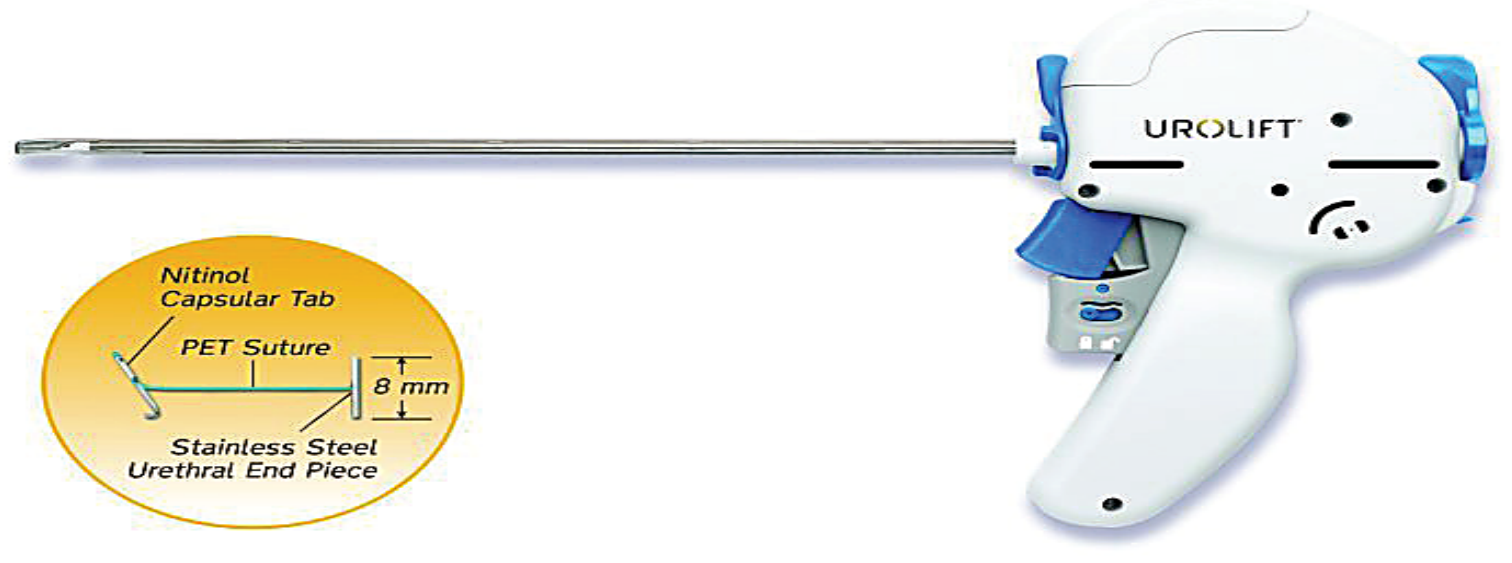

Urolift Implant

Urolift Delivery Device

and was keen to pursue a surgical intervention in a bid to improve his symptoms without the need to take medication. He was also reluctant to pursue TURP due to the risks of bleeding, sexual dysfunction including risk to prosthesis, and catheter. He therefore wished to explore the option for UroLift.

His past medical history was for significant cardiac disease, with ST-elevated myocardial infarct in 1998 and a cardiac arrest in 2012. The patient had an implanted cardiac device for ventricular tachycardia and severe left-ventricular systolic dysfunction. His other co-morbidities included chronic obstructive pulmonary disease, hypertension, hypercholesterolemia, non-insulin dependent diabetes and chronic kidney disease stage 3. His drug history is for amiodarone, apixaban, and ramipril.

His past surgical history is for an IPP for ED following failed conservative and medical treatments. This operation was performed in February 2008; the device used is the AMS 700 MS IPP (Figure 2).

The initial urology consultation was at his local unit that did not offer UroLift. The patient was subsequently referred to Hereford County Hospital for consideration of surgery.

\section{ASSESSMENT AND INVESTIGATIONS FOR UROLIFT}

The patient was investigated with a transrectal ultrasound revealing 45-cc prostate. A flow study was performed that found a Qmax of $6.8 \mathrm{~mL} / \mathrm{s}$ and a post-void residual of $69 \mathrm{mLs}$. A flexible cystoscopy was also performed for completeness to assess for suitability for UroLift. Cystoscopy demonstrated no urethral strictures, a long prostatic urethra with bilateral obstructive prostatic lobes, no middle lobe, and normal bladder urothelium.

Following these investigations, the patient was considered suitable for UroLift. It was considered pertinent for anesthetic assessment given his extensive cardiac history. He was deemed suitable for general anesthesia with advice to stop apixaban for 48 hours prior to the procedure. The patient was extensively counselled in accordance with the new British Association of Urological Surgeons (BAUS) guidelines for UroLift ${ }^{3}$ to include documented risks and complications. It was difficult to counsel the patient with regards to risk of damage to the prosthesis as no data was found despite extensive literature searches. The UK and US representatives were also unaware of any data or similar cases. After extensive patient counselling, the patient was happy to proceed fully aware of the unknown risk to the prosthesis.

\section{OPERATIVE TECHNIQUE}

UroLift was performed as day case at Hereford County Hospital. A 160-mg dose of gentamicin was 
FIG. 2 AMS 700 Penile Prosthesis. Material provided courtesy of Boston Scientific. Copyright 2018 (C) Boston Scientific Corporation or its affiliates. All rights reserved.

\section{AMS $700^{\text {tw }}$ \\ Inflatable Penile Prosthesis}

Image courtesy of Boston Scientific. 6 Boston Solentific 2017 - Do not copy or distribute

J Endolum Endourol Vol 2(1):e5-e12; January 14, 2019.

This article is distributed under the terms of the Creative Commons Attribution-Non

Commercial 4.0 International License. (C2019 Jones et al. 
administered at induction of general anesthesia. The intra-operative findings were occlusive lateral lobes of the prostate, with the left lobe being the more occlusive. There were 3 implants to the left lobe and one implant to the right. The left-sided implants were placed at $2 \mathrm{~cm}$ below the bladder neck, the level of the mid prostate, and the verumontanum. The right-sided implant was placed at the mid prostate. It is important to note that no special surgical adjustments were made in consideration of the prosthesis and a "standard" UroLift technique was used. A large prostatic urethra was achieved after applying the implants (Figure 3). There were no immediate complications to the IPP.

The total theatre time (including anesthetic) was 37 minutes, the operative time was 12 minutes and the total hospital stay was 6 hours.

Post-operatively, there were no immediate concerns and the patient was discharged on the same day voiding well. Telephone consultation one week after the operation confirmed no complications to the IPP that remained fully functioning. The patient awaits follow up at 4 months post-procedure with a repeat flow study.

\section{DISCUSSION}

Male LUTS are defined by NICE as storage, voiding, and post-micturition symptoms. ${ }^{2}$ The incidence increases with age and the most common cause is BPH. This can affect up to $30 \%$ of men over the age of 65 , with Kirby et al. reporting that BPH affects 3.2 million men in the UK. ${ }^{4}$

The treatment for male LUTS consists of medical therapy as a first-line, this includes alpha-blockers or 5-alpha reductase inhibitors. ${ }^{2}$ Surgical intervention is offered when medical therapy fails, and the current gold standard is TURP surgery. ${ }^{5}$

The success of TURP surgery is suggested by significant improvement in patient symptoms scores, improved flow rate studies, and reduction in post-void

FIG. 3 (A) Pre UroLift implant deployment image of the prostate demonstrating a prominent left lobe. (B) Post UroLift channel created.

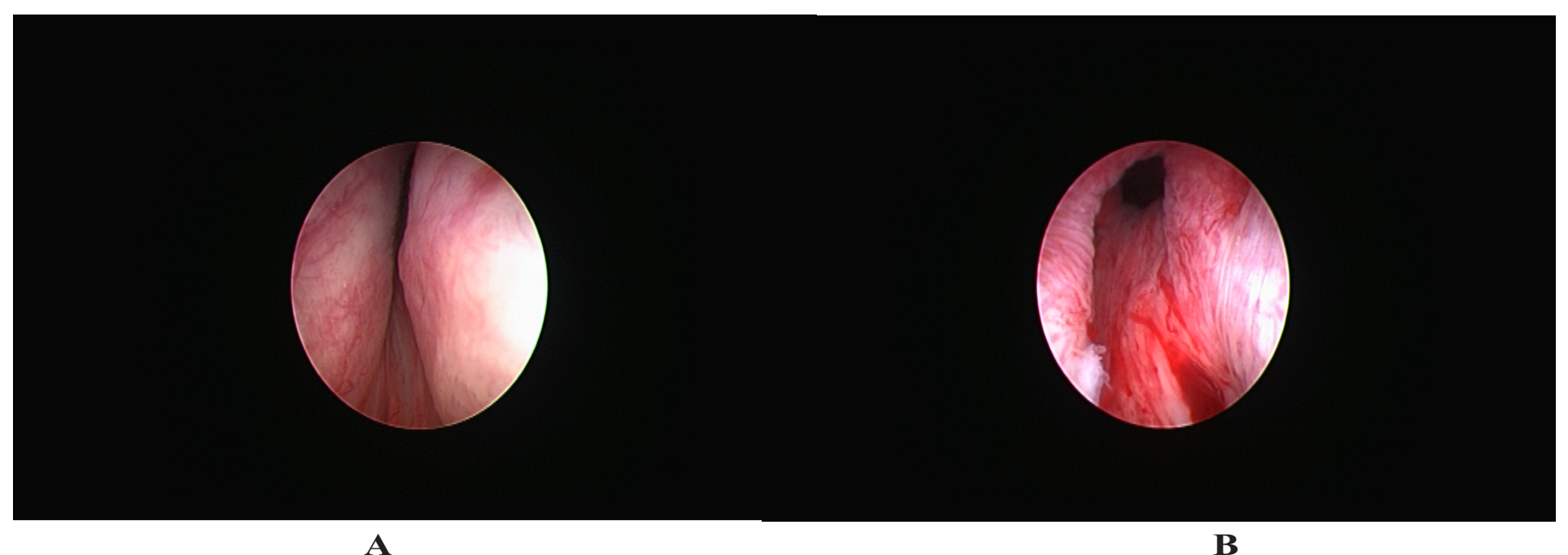

J Endolum Endourol Vol 2(1):e5-e12; January 14, 2019.

This article is distributed under the terms of the Creative Commons Attribution-Non

Commercial 4.0 International License. (C2019 Jones et al. 
residual volumes. ${ }^{6}$ There are however, well-documented risks associated with TURP surgery that include ED $(2-10 \%)$ and incontinence $(2-10 \%){ }^{7}$

The UroLift device (Teleflex Inc.) is a non-ablative, minimally invasive option for managing male LUTS as a result of $\mathrm{BPH} .{ }^{1}$ The UroLift procedure is undertaken transurethrally with either general or local anesthesia. ${ }^{8}$ The UroLift device works by introducing a single-use, pre-loaded delivery device through a rigid sheath under cystoscopic visualization. The delivery device then deploys permanent, trans-prostatic, Nitinol implants to retract the lobes of the prostate towards the capsule. ${ }^{8}$ Typically, multiple implants are used to retract the obstructing lateral lobes and create an open, continuous voiding channel ${ }^{1}$ (Figure 4).

There are multiple advantages for use of the UroLift device over TURP surgery for LUTS resulting from BPH. ${ }^{9}$ UroLift is considerably less invasive and can be performed under local anesthesia, it has reduced sexual dysfunction, and has shorter operative times. ${ }^{10}$ As a result, the UroLift procedure can be performed as a day case procedure, which in turn alleviates bed pressures in NHS trusts. ${ }^{9}$

Outcomes following UroLift are favourable and there have been multiple studies confirming that it is an effective method for managing LUTS due to BPH. Bardolli et al. ${ }^{9}$ reported 11 cases of UroLift in a single-centre cohort study demonstrating a reduction in IPSS at 4 months post-operatively of -9.1 (mean pre-operative IPSS $=25.4$, mean post-operative $=$ 16.3, $\mathrm{p}=0.02) .^{9}$ There was also reduction in PVR volume at 4 months with a pre-operative mean of $300.1 \mathrm{~mL}$ to $193.8 \mathrm{~mL}$ post-operatively (difference $=$ $-106.3 \mathrm{~mL}, \mathrm{p}=0.04)$. Bardoli et al. also reported significant improvement in QoL scores (5.1 vs. 3.5, difference -1.6). ${ }^{9}$
Further, Roehrborn et al. conducted a prospective, multi-centre, randomized, blinded sham control trial of the use of PUL for LUTS in BPH (L.I.F.T study). ${ }^{11}$ This study reported that use of PUL techniques offer rapid improvement in symptoms, QoL and flow rates, and that these were durable for 5 years post-operatively. There was also preservation of both erectile and ejaculatory function and that this was stable over the 5-year period. ${ }^{11}$

$\mathrm{BPH}$ is also associated with sexual dysfunction that can include ED. ED is defined as the inability to achieve and maintain a penile erection adequate for satisfactory sexual intercourse. ${ }^{12}$ Demir et al. reported that patients with severe LUTS had significantly lower IIEF erectile function scores than those with moderate LUTS. ${ }^{13}$

$\mathrm{ED}$ is a very common disorder, and the incidence and prevalence is high worldwide. The Massachusetts Male Aging Study reported an overall prevalence of $52 \%$ of ED in those between $40-70$ years. ${ }^{14}$ It is predicted that 322 million men will be affected by the year 2025. ${ }^{15}$ Increasing age correlates most strongly with rates of ED. The incidence of moderate ED doubles from $17 \%$ to $34 \%$ between the ages of 40 and 70 , and those with severe ED tripling from 5\% to $15 \%{ }^{16}$

This condition can severely impact a patient's QoL, and there are many medical and surgical interventions to try to manage ED. According to the EAU male sexual dysfunction guidelines, ${ }^{17}$ the use of a penile prosthesis is considered as third-line treatment option for ED, with 2 types of prosthesis available; these include malleable type or inflatable type. ${ }^{18}$

Scott et al. designed and developed the first IPP ${ }^{19}$ in 1973. Since its development, advances in materials and surgical technique have allowed for product enhancements and improved patient satisfaction. ${ }^{20}$

FIG. 4 UroLift procedure and deployment of implants to increase the diameter of the prostatic urethra. Images provided courtesy of Teleflex Inc.. All rights reserved.

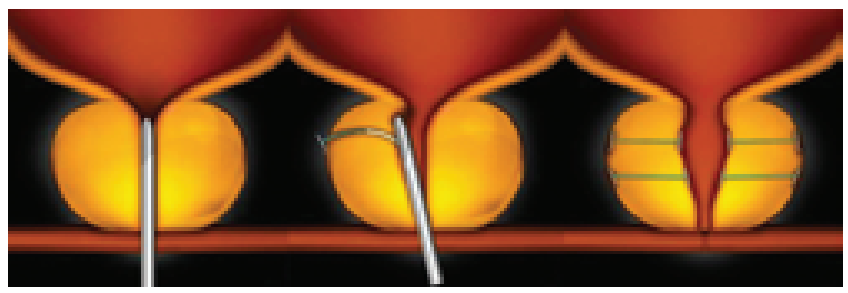

J Endolum Endourol Vol 2(1):e5-e12; January 14, 2019.

This article is distributed under the terms of the Creative Commons Attribution-Non

Commercial 4.0 International License. (C2019 Jones et al. 
There is also greater mechanical reliability of more modern implants, with Wilson et al. reporting $79.4 \%$ of implants having a reported rate of freedom of mechanical breakage at 10 years. ${ }^{21}$

Despite these advances, it remains well documented that reduction in penile length remains an issue postinsertion. This continues to negatively affect the IIEF satisfaction scores. ${ }^{22}$ As a result, the American Medical Service (AMS) designed and produced the AMS 700 IPP in 2006, its introduction aimed to minimize penile shortening associated with IPP surgery. ${ }^{23}$

The AMS 700 MS IPP is an implantable, closed fluid-filled system used for ED. ${ }^{24}$ It consists of 2 cylinders, 1 pump, and a fluid reservoir that stores fluid to expand the penile cylinders. The patient operates the pump to inflate the cylinders by squeezing the pump; this transfers fluid from the reservoir to the cylinders, in turn making the penis erect. Detumescence is achieved by deflating the cylinders by pressing a deflation button for 2-4 seconds. In doing so, fluid is transferred back into the reservoir and makes the penis flaccid ${ }^{24}$ (Figure 5).
The reservoir is traditionally placed in the prevesical or retroperitoneal space. The initial steps for introduction of the reservoir are the same. This involves a transverse infra umbilical incision and the pubic tubercle is used as a landmark for gaining entry into the superficial inguinal ring. Commonly, in men who have had no prior pelvic surgery, the reservoir is placed posterior to the transversalis fascia. ${ }^{25}$ As the images suggest, there is close proximity of the working elements of the IPP to the operative fields for UroLift (see Figure 2). This may result in damage to the IPP when using the UroLift device.

\section{CONCLUSION}

We report our experience of using the UroLift device in the presence of an inflatable penile prosthesis to manage LUTS caused by BPH. To our best knowledge, there is no published literature on surgical technique for this unique case. By using the standard UroLift technique, we surmise that it is safe to perform the UroLift procedure in such cases following appropriate patient counselling on the risks to the prosthesis.

FIG. 5 AMS 700 MS penile implant. Material provided courtesy of Boston Scientific Copyright 2018 (C) Boston Scientific Corporation or its affiliates. All rights reserved.

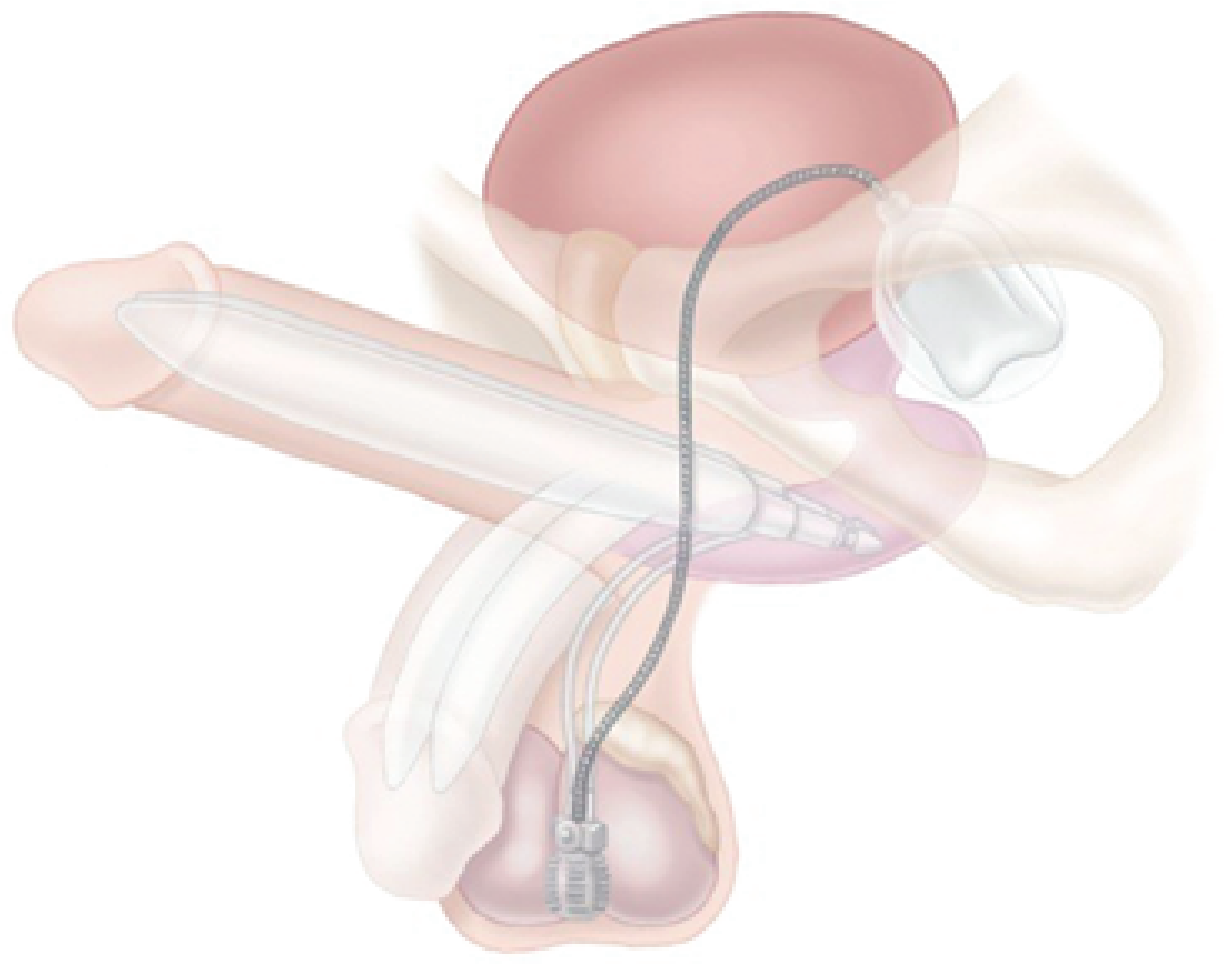

J Endolum Endourol Vol 2(1):e5-e12; January 14, 2019.

This article is distributed under the terms of the Creative Commons Attribution-Non

Commercial 4.0 International License. (C2019 Jones et al. 


\section{FUNDING AND CONFLICT OF INTEREST}

There was no funding received for the production of this manuscript. There was no conflict of interest from the authors involved.

\section{ACKNOWLEDGEMENTS}

The authors would like to thank Boston Scientific Corporation and Teleflex Incorporated for permission of the images included in the figures used throughout the manuscript.

\section{REFERENCES}

1. Jones P, Rai BP, Aboumarzouk O et al. UroLift: a new minimally-invasive treatment for benign prostatic hyperplasia. Ther Adv Urol 2016;8(6):372-76.

2. National Institute for Health and Care Excellence. UroLift for treating lower urinary tract symptoms of benign prostatic hyperplasia (MTG26). http://nice.org .uk/guidance/mtg26. Published 16.09.2015.

3. British Association of Urological Surgeons. Prostatic urethral lift (UroLift) implant. September 2017. https:// www.baus.org.uk/_userfiles/pages/files/Patients/ Leaflets/Urolift.pdf

4. Kirby RS, Kirby M, Fitzpatrick JM. Benign prostatic hyperplasia: counting the cost of its management. BJU Int 2010;105:901-902.

5. Mishriki SF, Grimsley SJ, Nabi G et al. Improved quality of life and enhanved satisfaction after TURP: prospective 12-year follow-up study. Urology 2008;72:322-26.

6. Ahyai S, Gilling P, Kaplan S et al. Meta-analysis of functional outcomes and complications following transurethral procedures for lower urinary tract symptoms resulting from benign prostatic enlargement. Eur Assoc Urol 2010;58:384-97.

7. British Association of Urological Surgeons (BAUS). Transurethral Prostatectomy (TURP) for benign disease - information about your procedure from BAUS (Internet). Available from: https://www.baus.org. uk/_userfiles/pages/files/Patients/Leaflets/TURP\%20 for\%20benign.pdf

8. Ray A, Morgan H, Wilkes A et al. The UroLift system for the treatment of lower urinary tract symptoms secondary to benign prostatic hyperplasia: A NICE medical technology guidance. Appl Health Econ Health Policy 2016;14;515-26.

9. Bardoli AD, Taylor WST, Mahmalji W. Can the UroLift prostatic implant device treat the symptoms of benign prostatic hypertrophy, avoid sexual dysfunction and reduce hospital TURP waiting times? A single centre, single surgeon experience and review of the literature. Aging Male. 2017;20(3):192-97. doi: 10.1080/13685538.2017.1336531. Epub 2017 Jun 13.

10. Bardoli AD, Taylor WST, Cobley J et al. Is there a minimally invasive day case operation to treat LUTS secondary to BPH and avoid sexual dysfunction? UroLift a case report. J Men's Health 2017;14(1):e1-e3.

11. Roehrborn CG, Barkin J, Gange SN et al. Five year results of the prospective randomized controlled prostatic urethral L.I.F.T study. Can J Urol 2017;24(3):8802-13.

12. Munir A, Kalsi J, Nazareth I et al. Erectile dysfunction. BMJ 2014;348:g129.

13. Demir O, Akgul K, Akar Z et al. Association between lower urinary tract symptoms and sexual dysfunction assessed using the core lower urinary tract symptom score and International Index of Erectile Function-5 questionnaires. Aging Male 2012;15:111-14.

14. Feldman HA, Johannes CB, Derby CA et al. Erectile dysfunction and coronary risk factors: prospective results from the Massachusetts male aging study. Prevent Med 2000;30(4):328-38.

15. Rajendran R, Cummings M. Erectile dysfunction: assessment and management in primary care. Prescrib Pract 2014;25-30.

16. Khera M. Erectile dysfunction. BMJ Clin Evid 2011;2011:1803.

17. Hatzimouratidis K, Earldey I Giuliano F et al. EAU guidelines on male sexual dysfunction: Erectile dysfunction and premature ejaculation. European association of urology 2014. https://uroweb.org/wp-content/ uploads/14-Male-Sexual-Dysfunction_LR.pdf

18. Castiglione F, Ralph D, Muneer A. Surgical techniques for managing post-prostatectomy erectile dysfunction. Curr Urol Rep 2017;18(11):90.

19. Scott FB, Bradley WE, Timm GW. Management of erectile impotence. Use of implantable prosthesis. Urology 1973;2:80-2.

20. Knoll D, Henry G, Culkin D et al. Physician and patient satisfaction with the new AMS 700 momentary squeeze inflatable penile prosthesis. J Sex Med 2009;6:1773-78.

21. Wilson SK, Ckeves MA, Delk JR. Ulter cylinders: problems with uncontrolled lengthening (the S-shape deformity). J Urol 1996;155:135-37. 
22. Wang R, Howard GE, Hoang A et al. Prospective and long-term evaluation of erect penile length obtained with inflatable penile prosthesis to that induced by intracavernosal injection. Asian J Androl 2009;11:411-5.

23. Negro CL, Paradiso M, Rocca A et al. Implantation of AMS 700 LGX penile prosthesis preserves penile length without the need for penile lengthening procedures. Asian J Androl 2016;18:114-17.
24. AMS 700 with MS Pump Penile Prosthesis. Operating room manual. Boston Scientific 2017. Online https:// www.bostonscientific.com/content/dam/Manuals/us/ current-rev-en/92127382-01B_AMS_700_ORM_en_s.pdf

25. Stember DS, Kohler TS, Morey AF. Management of perforation injuries during and following penile prosthesis surgery. J Sex Med 2015;12:456-61. 